\title{
Diverse methanogens, bacteria and tannase genes in the feces of the endangered volcano rabbit (Romerolagus diazi)
} \author{
Romero ${ }^{\text {Corresp., } 2}$, José Antonio Guerrero ${ }^{\text {Corresp. } 1}$ \\ 1 Facultad de Ciencias Biológicas, Universidad Autónoma del Estado de Morelos, Cuernavaca, Morelos, Mexico \\ ${ }^{2}$ Centro de Ciencias Genómicas, Universidad Nacional Autónoma de México, Cuernavaca, Morelos, Mexico \\ 3 Red de Estudios Moleculares Avanzados, Instituto de Ecología, A.C., Xalapa, Veracruz, México \\ 4 Escuela Nacional de Ciencias Biológicas, Instituto Politécnico Nacional, Ciudad de México, México \\ Corresponding Authors: Esperanza Martinez-Romero, José Antonio Guerrero \\ Email address: emartine@ccg.unam.mx, aguerrero@uaem.mx
}

Leslie M. Montes-Carreto ${ }^{1}$, Jose Luis Aguirre-Noyola ${ }^{2}$, Itzel A. Solís-García ${ }^{3}$, Jorge Ortega ${ }^{4}$, Esperanza Martinez-

Background. The volcano rabbit is the smallest lagomorph in Mexico, it is monotypic and endemic to the Trans-Mexican Volcanic Belt. It is classified as endangered by Mexican legislation and as critically endangered by the IUCN, in the Red List. Romerolagus diazi consumes large amounts of grasses, seedlings, shrubs, and trees. Pines and oaks contain tannins that can be toxic to the organisms which consume them. The volcano rabbit microbiota may be rich in bacteria capable of degrading fiber and phenolic compounds.

Methods. We obtained the fecal microbiome of three adults and one young rabbit collected in Coajomulco, Morelos, Mexico. Taxonomic assignments and gene annotation revealed the possible roles of different bacteria in the rabbit gut. We searched for sequences encoding tannase enzymes and enzymes associated with digestion of plant fibers such as cellulose and hemicellulose. Results. The most representative phyla within the Bacteria domain were: Proteobacteria, Firmicutes and Actinobacteria for the young rabbit sample (S1) and adult rabbit sample (S2), which was the only sample not confirmed by sequencing to correspond to the volcano rabbit. Firmicutes, Actinobacteria and Cyanobacteria were found in adult rabbit samples S3 and S4. The most abundant phylum within the Archaea domain was Euryarchaeota. The most abundant genera of the Bacteria domain were Lachnoclostridium (Firmicutes) and Acinetobacter (Proteobacteria), while Methanosarcina predominated from the Archaea. In addition, we obtained 18 bacterial tannase sequences. The potential functions of these sequences were identified which include carbohydrate and amino acid metabolism. We also found genes encoding enzymes for plant fiber degradation such as $\beta$-1-4-endoglucanases, xylanases, $\beta$-glucosidases and arabinofuranosidases. 


\section{Diverse methanogens, bacteria and tannase genes in}

\section{2 the feces of the endangered volcano rabbit}

\section{3 (Romerolagus diazi)}

4

5 Leslie M. Montes-Carreto ${ }^{1}$, Jose Luis Aguirre-Noyola ${ }^{2}$, Itzel A. Solís-García ${ }^{3}$, Jorge Ortega ${ }^{4}$, 6 Esperanza Martinez-Romero ${ }^{2}$, José Antonio Guerrero ${ }^{1}$

${ }^{1}$ Facultad de Ciencias Biológicas, Universidad Autónoma del Estado de Morelos, Cuernavaca, Morelos, México.

${ }^{2}$ Centro de Ciencias Genómicas, Universidad Nacional Autónoma de México, Cuernavaca, Morelos, México.

${ }^{3}$ Red de Estudios Moleculares Avanzados, Instituto de Ecología, A.C, Xalapa, Veracruz, México.

${ }^{4}$ Escuela Nacional de Ciencias Biológicas, Instituto Politécnico Nacional, Ciudad de México, México.

Corresponding authors:

José Antonio Guerrero ${ }^{1}$

Facultad de Ciencias Biológicas, Universidad Autónoma del Estado de Morelos, Cuernavaca, Morelos, México

Email address: aguerrero@uaem.mx

\section{Esperanza Martinez-Romero ${ }^{2}$}

Centro de Ciencias Genómicas, Universidad Nacional Autónoma de México, Cuernavaca, Morelos, México.

Email address: emartine@,ccg.unam.mx

\section{Abstract}

Background. The volcano rabbit is the smallest lagomorph in Mexico, it is monotypic and endemic to the Trans-Mexican Volcanic Belt. It is classified as endangered by Mexican legislation and as critically endangered by the IUCN, in the Red List. Romerolagus diazi 
32 consumes large amounts of grasses, seedlings, shrubs, and trees. Pines and oaks contain tannins

33 that can be toxic to the organisms which consume them. The volcano rabbit microbiota may be

34 rich in bacteria capable of degrading fiber and phenolic compounds.

35 Methods. We obtained the fecal microbiome of three adults and one young rabbit collected in

36 Coajomulco, Morelos, Mexico. Taxonomic assignments and gene annotation revealed the

37 possible roles of different bacteria in the rabbit gut. We searched for sequences encoding tannase

38 enzymes and enzymes associated with digestion of plant fibers such as cellulose and

39 hemicellulose.

40 Results. The most representative phyla within the Bacteria domain were: Proteobacteria,

41 Firmicutes and Actinobacteria for the young rabbit sample (S1) and adult rabbit sample (S2),

42 which was the only sample not confirmed by sequencing to correspond to the volcano rabbit.

43 Firmicutes, Actinobacteria and Cyanobacteria were found in adult rabbit samples S3 and S4. The

44 most abundant phylum within the Archaea domain was Euryarchaeota. The most abundant

45 genera of the Bacteria domain were Lachnoclostridium (Firmicutes) and Acinetobacter

46 (Proteobacteria), while Methanosarcina predominated from the Archaea. In addition, we

47 obtained 18 bacterial tannase sequences. The potential functions of these sequences were

48 identified which include carbohydrate and amino acid metabolism. We also found genes

49 encoding enzymes for plant fiber degradation such as $\beta$-1-4-endoglucanases, xylanases, $\beta$ -

50 glucosidases and arabinofuranosidases.

51

52 Key words: microbiome, fecal metagenome, herbivorous animals, tannase enzymes, volcano

53 rabbit

54 Introduction 
regions of the body, such as skin, mucous membranes, gastrointestinal tract, among others

57 (Muegge et al. 2011). Microbiota is defined as a microbial community living in an anatomical

58 site, self-regulating their abundance and metabolic dynamics, which can influence the health status of the host. Microbiome is the term used to designate the genome of the microbiota (Redinbo 2014; Ventura et al. 2009). Herbivores have been characterized as having a larger microbial diversity in their guts than omnivores or carnivores (Ley et al. 2008). Bacterial symbionts expand the host digestion spectrum by fermenting cellulose and hemicellulose (Ley et al. 2008; Tilg 2010). Individual/intrinsic factors that includes age, sex, genetics, host phylogeny and environmental/extrinsic factors like diet and habitat conditions could change the microbial community of the rabbit gut (Funosas et al. 2021; North et al. 2019). $95 \%$ ) and stable temperature of $35-40^{\circ} \mathrm{C}$. The transit speed of particles and food fluids is slower (27 and 39 hours respectively) compared to other species as the guinea pig (13 hours), rat (22 and 20 hours) and horse (25 and 20 hours) (Velasco-Galilea et al. 2018). The rabbit gut microbial community is composed of 100-1000 billion microorganisms per gram of cecal, belonging to 1000 different species of microorganisms (Combes et al. 2011). Bacteria belonging to Lachnospiraceae, Clostridiaceae, and Ruminococcaceae families play an important role in the digestion of cellulose and hemicellulose as they may produce short-chain fatty acids (Biddle et al. 2013). In addition, other families that include Desulfovibrionaceae, Eubacteriaceae, Bacteroidaceae, Christensenellaceae, Erysipelotrichaceaea, Rikenellaceae and Spirochaetaceae have been reported in lagomorphs (North et al. 2019; Shanmuganandam et al. 2020; Stalder et al. 77 2019). 
Diet is considered one of the factors modeling the microbial community in all animals

79

80

and this is also the case with hindgut-fermenter animals like rabbits (Muegge et al. 2011).

Moreover, rabbits are caecotrophagic animals (they ingest their own soft fecal pellets produced

by digestion in the cecum) profiting from the nutrients in feces derived from microbial fermentation (Crowley et al. 2017). Fecal ingestion would allow a second digestion of plant fibers, a process that could be considered analogous to ruminant digestion. Coprophagy is as well a very efficient way to recycle gut microbiota (Martinez-Romero et al. 2020). In most lagomorph studies, Firmicutes were found as the most abundant bacteria (North et al. 2019; Stalder et al. 2019; Velasco-Galilea et al. 2018) followed by Bacteroidetes (North et al. 2019; Stalder et al. 2019), although Crowley et al. (2017) found that both Bacteroides and Firmicutes were equally abundant. Proteobacteria were found to be more abundant in cecal samples (North et al. 2019), which differs from the results with fecal samples investigated in other papers (Velasco-Galilea et al. 2018; Shanmuganandam et al. 2020). It should be noted that Illumina 16S v3-v4 sequencing led to an underrepresentation of Firmicutes (Shanmuganandam et al. 2020). Firmicutes and Bacteroidetes are the dominant phyla in human guts (Human Microbiome Project 2012) and therein the Firmicutes/Bacteroidetes ratio is not constant and changes with age (Mariat et al. 2009) and in some cases with obesity (Magne et al. 2020).

The volcano rabbit (Romerolagus diazi) is an endemic species classified as endangered by Mexican legislation (SEMARNAT 2010) and as critically endangered in the IUCN Red List (Velázquez \& Guerrero 2019). It plays an important ecological role as part of the diet of carnivorous mammals, prey for birds and reptiles (Cervantes \& Martínez-Vázquez 1996; Uriostegui Velarde et al. 2015). Besides, the volcano rabbit consumes large amounts of vegetative parts of grasses, seedlings, shrubs, trees and can regulate plant composition and seed 
101 dispersal processes (Granados-Sánchez et al. 2004). The diet of the volcano rabbit is based on

102 grasses but is complemented with other plants. Previously, 37 plant species were identified in its

103 diet, 80\% of which were grasses such as Muhlenbergia macroura, Festuca amplissima and

104 Jarava ichu. In addition, the consumption of leaves of Phoradendron velutinum, Pinus sp, and

105 Quercus laurina was recorded (Mancinez Arellano 2017). Pines and oaks contain chemical

106 compounds that can be toxic to the organisms that consume them. These toxins are considered to

107 have a defensive role against animals (Granados-Sánchez et al. 2008). The aim of this study was

108 to describe the microbes found in the volcano rabbit feces to assess their role in plant fiber and

109 tannin degradation, because tannins are important constituents of their diet. We surmised that the

110 fecal microbiome of the volcano rabbit would reflect its herbivorous diet as observed in other

111 animals (Martinez-Romero et al. 2020) with a plethora of genes encoding enzymes to degrade

112 plant fibers and phenolics.

113

114 Materials \& Methods

115 Sample collection

116 Four fecal samples were collected from Coajomulco, Morelos Mexico (14Q UTM

$117478960.07 \mathrm{~m}$ E, $2109691.32 \mathrm{~m} \mathrm{~N}$ ) under a permit by Secretaría de Medio Ambiente y Recursos

118 Naturales (SGPA/DGVS/006985/18). These pellets are ochre in color, with a smooth, shiny

119 texture and their maximum diameter is one centimeter in adults. We kept more than $25 \mathrm{~m}$

120 between one latrine and another within a collection site, this distance is the estimated home range

121 for these rabbits (Cervantes \& Martínez-Vázquez 1996), except for two samples (S1 and S2) that

122 were collected in the same latrine with $0.1 \mathrm{~m}$ distance between them, but the pellets were of 
123 different sizes. Feces were stored individually in Eppendorf-type tubes in an icebox and later

124 taken to the laboratory and stored in a refrigerator at $4{ }^{\circ} \mathrm{C}$ for 6 hours.

125

126

127

128

129

130

131

132

133

134

135

136

137

138

139

140

141

142

143

144

145

\section{DNA extraction, sequencing, and Illumina library generation}

Total DNA of the four samples was extracted using the commercial DNA Isolation Kit from Roche Life Science. A total of $230 \mathrm{mg}$ of feces were processed for each sample. DNA concentration was measured by Nanodrop (Thermo Scientific) and Qubit ${ }^{\mathrm{TM}}$ dsDNA HS Assay

Kits) and the quality was determined by visualization in a $1 \%$ agarose gel. Samples requirements for the preparation of the libraries were: DNA concentration $>200 \mathrm{ng} / \mu \mathrm{l}$, total amount of DNA $>$ $1 \mu \mathrm{g}$ and DNA bands visualized in agarose had to be clear and of good quality. The genomic DNA was randomly cut into small fragments and subcloned into a "universal" cloning vector.

The sub fragment library was randomly sampled, and several sequences reads (using a universal primer that directs sequencing from within the vector) were generated from both strands. Sequencing was obtained with Illumina HiSeq 4000 using paired-end $2 \times 151 \mathrm{bp}$, at the sequencing unit Functional Genomics Laboratory at UC Berkeley, California.

\section{Sequence filtering and metagenome assembly}

Raw fastq reads were quality filtered with FASTP 0.20.0 (Chen et al. 2018). We considered good quality reads when the quality score was equal to or greater than 30 . Clean reads were mapped against genomes such as human, rat, rabbit, yeast, mouse, pine, oak, fly, worm, adapters, and pika to know whether the reads had contamination using FastQ Screen 0.14.0 (Wingett \& Andrews 2018). Data is available in the SRA at NCBI, BioProject:

PRJNA721235, Accession number: SRR14209496, SRR14209495, SRR14209494, SRR14209493). Metagenome assembly was performed using metaSPADES 3.12.0 (Nurk et al. 2017) and MEGAHIT 1.1.3 ( $\mathrm{Li}$ et al. 2015). Comparison of the assemblies was conducted to 
146 identify the best assembly with MetaQUAST 5.0.2 (Mikheenko et al. 2016). A good quality

147 assembly considers the proportion of contigs $<1000 \mathrm{nt}$, total length of the contigs, longest contig,

148 N50 (length), L50 (position), fewer contigs and identifying single-copy genes (>90\%) (Nurk et

149 al. 2013). Clean reads (R1 and R2) were aligned to each corresponding assembly to obtain the

150 percentage of reads that were assembled using Bowtie2 2.4.2 (Langmead \& Salzberg 2012). We

151 confirmed that the samples were from volcano rabbits because we encountered DNA sequences

152 in feces that matched those reported from the same rabbit species using the nucleotide sequences

153 of the cytochrome $b$ gene. We assessed taxonomic identity on fecal samples using Blast 2.10.0+

154 (Camacho et al. 2009) and a phylogenetic reconstruction using maximum likelihood (ML).

155 Additional sequences of related organisms were obtained by Blast 2.10.0+ at NCBI. Sequences

156 were aligned with Mafft 7.149b (Katoh \& Standley 2013). The best substitution model

157 (TPM2+F+G4) and ML analysis were performed with IQ-TREE 1.6.12 (Trifinopoulos et al.

158 2016).

159 Taxonomic Assignment

160 The microbial taxonomy assignation of each assembly per sample was estimated using

161 Kraken 2 2.0.8 (Wood et al. 2019). The abundance of the microbial community by phylum and

162 genus was estimated using Bracken 2.5.0 (Bayesian Abundance Re-estimation with KrakEN).

163 Bracken could reassign sequences that kraken 2 could not classify within the genus or species

164 levels with a reliable percentage above $98 \%$ (Lu et al. 2017). Both programs were run against a

165 Minikraken2_v1 database containing bacterial, archaeal genomes and viral libraries. In addition,

166 we searched for the 16S rRNA gene sequences in the metagenomes by Blast 2.10.0+. Redundant

167 sequences were removed with CD-HIT 4.8.1 (Li \& Godzik 2006). Phylogenetic reconstruction

168 was performed using the maximum likelihood (ML) method. Additional sequences of related 
169 organisms were obtained by Blast at NCBI and with the Refseq-RDP database. Sequences were

170 aligned with Mafft 7.149b. Spurious bases, editing and trimming were performed with trimAl 1.4

171 (Capella-Gutierrez et al. 2009). The best substitution model (GTR+F+R5) and ML analysis were

172 performed with IQ-TREE 1.6.12.

173 Alpha diversity and microbial composition

174 The microbial diversity of each sample at both phylum and genus level of Bacteria and 175 Archaea was estimated with the Hill numbers in terms of effective numbers of elements under 176 the same sample coverage (Chao \& Jost 2012). Hill numbers are a mathematically unified family

177 of diversity indices differing only by an exponent $q\left({ }^{q} \mathrm{D}\right)($ Chiu \& Chao 2016), where $q=0$ is

178 equivalent to species richness, $q=1$ corresponds to the exponential of Shannon entropy

179 (effective number of common elements), and $q=2$ is equivalent to the inverse of Simpson index, 180 interpreted as the effective number of dominant elements (Ma \& Li 2018; Ma et al. 2019). To

181 compare the microbial diversity between the four samples, we used the $95 \%$ confidence intervals

182 (CI), where no overlap between CI values indicates significant differences (Cumming et al.

183 2007). The qD diversity, sample coverage, and their respective confidence intervals were

184 obtained with the iNEXT R package 3.5.3 (Hsieh et al. 2016), using as endpoint the maximum

185 number of contigs in each sample and 1,000 bootstraps for the construction of the rarefaction

186 curves and CI.

187 The difference in composition of bacterial and archaeal communities was assessed by 188 one-way ANOSIM based on Bray-Curtis similarity metrics and with 10,000 permutations. When 189 the ANOSIM was significant, a pairwise comparison was conducted between samples using the 190 Bonferroni $p$-value correction as implemented in Past 4.2 (Hammer et al. 2001). This analysis 
191 was conducted considering only those genera with relative abundance equal to or greater than

$1920.5 \%$, meaning that rarely occurring microorganisms were not considered.

\section{Predicted functional annotation}

194 Gene annotation and coding sequence identification in feces microbiomes were

195 performed using Prokka 1.12 (Seemann 2014). One step for cleaning the protein fasta file-to

196 eliminate redundant sequences was performed using CD-HIT. We used blastp 2.10.0+ on the

197 sequences that Prokka did not score (hypothetical proteins) against the Uniprot-Sprot database.

198 Additionally, non-redundant protein fasta files of each sample were obtained. We performed a

199 second annotation of protein sequences with the online program GhostKOALA 2.2 (Kanehisa et

200 al. 2016), using GHOSTX search (it uses suffix arrays to find matching sequences and runs 100

201 times faster than BLAST), against a non-redundant set of KEGG genes (Kyoto Encyclopedia of

202 Genes and Genomes).

\section{Results}

204 Sequence and metagenome assembly

205 We extracted DNA from four fecal samples. According to the size of the collected feces,

$206 \mathrm{~S} 1(0.5 \mathrm{~cm})$ corresponded to a young individual, S2, S3 and S4 $(1.0 \mathrm{~cm})$ corresponded to adult

207 rabbits (Velázquez et al. 1996). We confirmed that the feces samples 1, 3, and 4 were from

208 volcano rabbits because we found cytochrome $b$ sequences in feces matched those reported

209 previously from the same rabbit species (Osuna et al. 2020). Although cytochrome $b$ sequence

210 was not detected from sample S2, we are confident that it corresponds to volcano rabbit as feces

211 of other rabbits inhabiting the zone are clearly distinctive (Velázquez et al. 1996). Maximum

212 likelihood analysis indicated that the cytochrome $b$ gene sequences found in the metagenomes

213 were phylogenetically placed with the volcano rabbit (Fig. S1). 
We obtained a total of 332.8 million raw reads from the four samples. Once the cleaning

215

was completed, we rescued 316.6 million reads and the average number of reads per sample was 79.15 million (ranging from 69.6 to 96.6 ) (Table S1). Extra filtering of the clean sequences was conducted to obtain external contamination. The results demonstrated that between $98.2 \%$ and $99.6 \%$ of the clean reads were not assigned to adapters, human, rat, rabbit, yeast, mouse, pine, oak, fly, worm, and pika genomes. Individual assemblies of each sample S1, S2, S3 and S4 were performed. Fewer and larger contigs were obtained with metaSPADES than with MEGAHIT. Moreover, $83 \%-85 \%$ of the clean reads were mapped against each assembly.

\section{Taxonomic assignment}

The percentage of contigs that could be classified ranged between $14 \%$ and $18 \%$ for the taxonomic levels of phylum and genus of the Bacteria and Archaea domains. This could be due to the limitations of the non-human database where rare species are present (Tamames et al. 2019). Twenty-nine phyla were obtained from the Bacteria domain (Fig. 1a). The phylum Proteobacteria was the most abundant in sample two (S2) and sample from the young rabbit (S1) that has been found in other young animals and humans (Moon et al. 2018). The most abundant phylum in samples S3 and S4 was Firmicutes. Additionally, we found three phyla of the Archaea domain: Euryarchaeota, Crenarchaeota and Thaumarchaeota with the most abundant being Euryarchaeota (Fig. 1b). Nine families were the most abundant in all samples (Table 1). The most abundant genus of the domain Bacteria in the young rabbit feces was Acinetobacter (Proteobacteria) while in adult-rabbit feces was Lachnoclostridium (Firmicutes) (Fig. 2a). Candidatus tachikawaea, Leclercia, Candidatus riesia, and Obesumbacterium were only found in the gut metagenome from young rabbit feces (Fig. 2a). The number of archaeal genera we encountered here in the fecal microbiome of the volcano rabbit is remarkable. We identified 15 
237 genera of the domain Archaea, Methanosarcina, Methanoculleus and Methanococcus were the

238 most abundant in all samples. The genus Halorabdus was the most abundant only in sample two

239 (Fig. 2b), which is the only sample for which there was no confirmation of host rabbit identity.

240 We recovered $16916 \mathrm{~S}$ rRNA sequences $(1273 \sim 1500 \mathrm{bp})$ from the assembled

241 metagenomes. Maximum likelihood analysis indicated that the 16S rRNA gene sequences found

242 in the metagenomes were phylogenetically placed in the following phyla: Firmicutes,

243 Bacteroidetes, Proteobacteria, Synergistetes, Tenericutes, Verrucomicrobia, Cyanobacteria,

244 Lentisphaerae and Spirochaetes (Fig. S2). Besides, we found some 16S rRNA gene sequences

245 that did not cluster with any reported phyla. Many 16S rRNA gene sequences were related to the

246 species Marvinbryantia formatexigens, which has been found in the human gut and has been

247 reported to degrade plant oligosaccharides (stachyose and raffinose) (Rey et al. 2010).

248 Alpha diversity and microbial composition

249 In all samples, at the phylum and genus level of Bacteria and Archaea showed a sample

250 coverage of $100 \%$, indicating that sampling is complete for all samples (Fig. 3). Then the

251 diversity comparisons were made directly according to their confidence intervals (Chao \& Jost

252 2012). For bacterial communities, the richness of S1 was significantly higher than in the other

253 samples, at both phylum (Fig. 4a) and genus level (Fig. 4c). For the phyla of Archaea domain,

254 the richness of both S1 and S2 were not significantly different while a similar pattern was

255 observed between S3 and S4 (Fig. 4b). Richness estimates at the genus level in both domains

256 differed significantly between all samples (Fig. 4c; Fig. 4d). The diversity values of the effective

257 number of common and dominant elements are shown in Table S2.

258 According to ANOSIM, community composition at Bacteria and Archaea domains was

259 not significantly different between samples $(p>0.05)$. For genera of domain Bacteria, the 
260 composition was significantly different between S1 and the other three samples $(p=0.0002)$,

261 while for the genera of domain Archaea the composition was significantly different between all

262 samples $(p=0.0002)$.

\section{Functional annotation}

A similar number of sequences was annotated from all samples $(101,832-138,018)$ in all

265

266

267

268

269

270

271

272

273

274

275

276

277

278

279

280

281

282 categories (Table 2). According to the function of their specific catalytic action, genes encoded oxidoreductases, transferases, hydrolases, lyases, isomerases, ligases, and translocases (Chang et al. 2021). The most abundant genes in all samples were transferases $(28,523-21,324$ sequences $)$ and hydrolases $(17,885$ - 24,675) followed by oxidoreductases $(10,797$ - 7,757$)$, ligases $(5,081$ $7,013)$, lyases $(4,896-6,064)$ and isomerases $(4,227-5,500)$, no translocase-type enzymes were found with the PROKKA annotation (Fig. 5). The highest number of annotations of all the enzymes $(82,572)$ was in S1 while the sample with the lowest number of annotated enzymes was S2 (61,201) (Fig. 5). Additional enzyme search using blastp showed between 954 - 1,125 total in different samples. Genes encoding translocases were recovered, which ranged from 16 to 37 sequences in the different samples. We found 21 functional categories. Protein Families $(17,065$ - 11,711 contigs per sample), genetic information processing $(17,065$ - 12,536), carbohydrate metabolism (glycolysis/gluconeogenesis, citrate cycle, TCA cycle; 12,571 - 9,776), protein families: signaling and cellular processes $(7,400-5,197)$ and amino acid metabolism $(7,103$ 5,730) were the most abundant in all samples. Meanwhile, xenobiotics biodegradation (127 - 58) and biosynthesis of secondary metabolites (49 - 66) had the lowest number of annotated sequences (Fig. 6).

Tannase enzyme sequences from different taxonomic groups were searched and downloaded from Uniprot and NCBI databases. Blastp search was performed to obtain the 
283 possible gene sequences for tannase enzymes. 18 sequences were found in the four metagenomic

284 samples of volcano rabbits that were affiliated to phylum Verrucomicrobia, family

285 Ruminococcaceae, Victrivallis vadensis, Blautia sp. and Clostridium sp. Finally, enzymes that

286 participate in the degradation of cellulose and hemicellulose of grasses were searched. The

287 highest number of sequences was obtained from young rabbit feces (849), while the lowest

288 number was obtained in S2 (526) (Fig. 7). The most abundant were endo 1,4 $\beta$-xylanases for

289 samples S1 (363) and S4 (248) and arabinofuranosidases for samples S2 (160) and S3 (149). The

290 enzymes found in lower proportion were those encoding $\beta$-glucosidases in sample S2 (94) and

291 Endo-glucanases in samples S3 (142) (Fig. 7).

292 Discussion

293 Gut microbiota

There are few studies on the microbiota of wild Lagomorphs. To our knowledge, this is 295 the first one to characterize the fecal microbiome of the volcano rabbit ( $R$. diazi) that is endemic to central highlands in Mexico. As an herbivore, the volcano rabbit would feed on plants that contain endophytes which may become part of the gut microbiota. This occurs in other herbivorous animals' endophytes that have tannases and enzymes to degrade plant cell wall components (Martinez-Romero et al 2020). A critical issue that should be considered is whether the microbiota identified from herbivorous animals represent bona fide gut bacteria or reflect endophytes that are still contained within the plant tissue fragments macerated during DNA extraction. Here a mild procedure not including physical maceration was performed and all plant debris was eliminated by centrifugation. 
306

307

308

309

310

311

312

313

314

315

316

317

318

319

320

321

322

323

324

325

326

327

differences among adult samples. Otherwise, differences could be due to the distinct lapse from fecal excretion and collection for which we have no record. Peculiarities of the gut microbiota of babies, infants and young animals have been recurrently reported, and here we corroborated this with the only young rabbit that was sampled. There are reports from three-week-old Asian elephants (Loxodonta cyclotis) (Ilmberger et al. 2014), young bats (Leptonycteris yerbabuenae) (Gaona et al. 2019) and puppies and kittens (Moon et al. 2018) where Proteobacteria are abundant. Since the gut of newborns is rich in oxygen, the role of Proteobacteria may be involved in oxygen consumption, thus preparing the neonatal gut for colonization by strict anaerobic microorganisms necessary for a healthy gut (Shin et al. 2015).

Here we report that the fecal microbiome of the volcano rabbit was dominated by Proteobacteria, Firmicutes, Actinobacteria, for S1 and S2 and Firmicutes, Actinobacteria and Cyanobacteria for S3 and S4. We suggest that the similarity between S1 and S2 may be due to the individuals being related because young rabbits tend to be close to their mothers and these samples were collected at the same location. However, we remark that in zoos and in houses, rabbits would have an artificial diet. It is also worth noting that fecal and gut bacteria are not the same and more Proteobacteria were found in intestinal samples than in fecal samples in the European brown hare (Stalder et al. 2019). Additionally, Proteobacteria has been reported to be more abundant in rabbits with the symptoms of epizootic rabbit enteropathy (ERE) (Bauerl et al. 2014) and in other mammals, such as bats (Artibeus lituratus) (Ingala et al. 2018) and Asian elephants with a high fruit diet (Budd et al. 2020). On the other hand, a study in New Zealand white rabbits has reported a high abundance of-Actinobacteria and Tenericutes (North et al. 2019). Phylum Lentisphaerae was previously reported in hares (L. europaeus). 
On the other hand, 16S rRNA reads from shotgun metagenomics provide sequences that

329

330

331

332

333

334

335

336

337

338

are not subject to PCR primer bias and covers taxa that are not detected by primer sets (Yuan et al. 2015); therefore, we complemented the kraken 2 taxonomic assignment with a global 16S rRNA gene bacterial identification and phylogeny from metagenomes. We obtained nine phyla out of 29 in the 16S rRNA analysis. Phylum Firmicutes was the most abundant in both. It has been reported that kraken 2 is suitable for the classification of gut microbiome with assemblies' recruit of $85 \%$ or more of the original raw reads (Tamames et al. 2019). Nevertheless, samples that have more diversity and complexity would not be correctly classified with kraken 2 . Less studied habitat metagenomes such as non-human environments show fewer similarities with kraken 2 which is quite sensitive to the composition of databases and their performance decreases when rare species are present in the metagenome (Tamames et al. 2019).

Domain Archaea has been reported in Caldes rabbit microbiome (Velasco-Galilea et al. 2018) with a single genus Methanobrevibacter (Euryarchaeota). Similarly, genus

Methanobrevibacter was identified in a molecular profiling from a rabbit caecum (Kusar, 2010). These differences could be due to different strategies to characterize microbiota (16S amplicon sequencing vs shotgun). Here we found an unusually high number (15) of archaeal genera in the

fecal microbiome of the volcano rabbit. Surprisingly, the most abundant genera were Methanosarcina, Methanoculleus, Methanococcus, Halorhabdus (Euryarchaeota) besides Methanobrevibacter. All of them have been found in the human gut microbiome (Borrel et al. 2020). Halorhabdus is usually associated with microaerophilic and halophilic environments. The axenic species described may use the monosaccharides glucose, fructose, and xylose for growth (Waino et al. 2000). Xylose is produced mainly in plants (wood, fibers, fruits) and as a degradation product of hemicellulose. Except for Halorhabdus, the other archaea may perform 
351 the terminal step in the degradation of organic matter and produce energy and methane through

352 methanogenesis pathways (Ferrer \& Pérez 2010; Ferry 2020). These methanogenic archaea are

353 generally associated with strict anaerobic environments, due to the high sensitivity to oxygen

354 exposure of the enzymes involved in methanogenesis and to the lack of genes that code for

355 proteins involved in protection against oxidative stress (Jasso-Chavez et al. 2015). Furthermore,

356 these methanogenic archaea use compounds with one or two carbons to grow, for the generation

357 of biosynthetic intermediates and polysaccharide storage (Santiago-Martinez et al. 2016).

358 Methanoculleus, Methanococcus and Methanobrevibacter use carbon dioxide plus hydrogen

$359\left(\mathrm{CO}_{2}+\mathrm{H}_{2}\right)$ and formate (HCOO-), while Methanosarcina uses more diverse carbon sources, e.g., 360 acetate $\left(\mathrm{CH}_{3} \mathrm{COO}-\right)$, methanol $\left(\mathrm{CH}_{3} \mathrm{OH}\right)$ and methylamines $\left(\mathrm{CH}_{3} \mathrm{NH}_{2}\right)$, plus $\mathrm{CO}_{2}+\mathrm{H}_{2}$ (Borrel et

361 al. 2020; Buan \& Robinson 2018). These compounds are produced by the metabolism of

362 eukaryotic and bacterial species. Specifically, there is evidence that the high intake of dietary

363 fiber in animals, followed by fermentation mediated by the intestinal microbiota, changes the

364 concentration and metabolism of methylamines ( $\mathrm{Li}$ et al. 2017), which are a very good carbon

365 source for methanogenic archaea. This suggests that the type of diet could increase the diversity

366 and abundance of methanogenic species. The diversity and abundance of methanogenic archaea

367 found in volcano rabbits may indicate a rich diversity of ingested vegetable and very complex

368 interaction between bacteria and archaea. Seemingly there is no competition for food between

369 these methanogenic and non-methanogenic archaea, due to the well-established difference in

370 preference for carbon sources.

\section{Prediction of functional annotation}

372 In the present study, we found several functional categories suggesting that the fecal

373 microbiome of $R$. diazi may have biosynthetic amino acid, carbohydrate metabolism, lipid 
374 metabolism, metabolism of terpenoids, polyketides and secondary metabolites and xenobiotic 375 biodegradation capabilities. Enzymes found in the fecal microbiome of the volcano rabbit were mainly transferases, hydrolases, and oxidoreductases enzymes. Categories such as carbohydrate metabolism and amino acid metabolism had been reported in other herbivores (Muegge et al. 2011). Pathways such as bile secretion, mineral absorption, and xenobiotics biodegradation have been obtained in other rabbits (Zeng et al. 2015). Recently, metabolism of terpenoids polyketides, amino acid metabolism carbohydrate, nucleotide metabolism, lipid metabolism, energy metabolism, and metabolism of cofactors and vitamins pathways were reported in African elephants (Budd et al. 2020).

Enzymatic activity of tannases was identified in phyla Firmicutes and Proteobacteria:

Enterobacter, Weissella and Lactobacillus (de las Rivas et al. 2019), Bacillus, Streptococcus,

Klebsiella, Enterococcus fecalis, Pantoea agglomerans, Staphylococcus lugdunensis,

386

387

388

389

390

391

392

393

394

395

396
Lactobacillus plantarum, L. paraplantarum (Rodríguez-Durán et al. 2010) and Bacillus

licheniformis (Palacio-Arango et al. 2018). In Koala feces, a Gram-negative, facultatively anaerobic and tannase-producing bacterium called Lonepinella koalarum was isolated (Osawa et al. 1995) which was not found in the microbiome of volcano rabbit feces pointing out the specialization or adaptation of some bacterial species to animal hosts.

Fiber degrading enzymes have been reported in bacteria such as Clostridium, Cellulomonas, Bacillus, Thermomonospora, Ruminococcus, Bacteroides, Erwinia and Streptomyces (Saratale et al. 2012). Clostridium was abundant in S2, S3 and S4 whereas Erwinia in S1. In all samples, we also found phylum Actinobacteria, which is abundant in soil producing secondary metabolites, antibiotics and related with degrading plant cell wall components (Saratale et al. 2012). 


\section{Conclusions}

398 The volcano rabbit microbiome showed distinct bacterial and archaea abundances

399 compared to other lagomorphs. We found genes that encode tannases and enzymes that degrade

400 the components of the plant cell wall in the volcano rabbit microbiome. The gut microbiota may

401 contribute to the digestion of complex plant molecules. Here we found many potential functional

402 categories such as metabolism of carbohydrates and biosynthesis of amino acids and other

403 compounds as secondary metabolites. The diversity of methanogenic species could be influenced

404 by the type of diet. In addition, we observed differences between the adults and young rabbit.

\section{Acknowledgements}

We thank all the colleagues from the FCB-UAEM for their help in the field work as well

407

as all the colleagues from the CCG-UNAM for their advice in bioinformatics tools. Dr. Julio

Guerrero from Umeå University for his assistance in the molecular assays. Dr. Lydia Smith from

UC Berkeley for contacting us with the sequencing unit. M.S. Gustavo Delgado from IBT-

410

UNAM for his assistance and advice with phylogeny and bioinformatics tools. Dr. Geovanni

411 Santiago from IIBO-UNAM for his helpful comments on archaea. Dr Mónica Rosenblueth from

412 CCG-UNAM for her helpful comments on the manuscript. Dr M. Dunn from CCG-UNAM for

413 critically reading the manuscript. Bioinformatic analyses were performed at CCG-UNAM. 


\section{References}

416

417

418

419

420

421

422

423

424

425

426

427

428

429

430

431

432

433

434

435

436

437

438

439

440

441

442

443

444

445

446

447

448

449

450

451

452

453

454

455

456

457

458

459

Bauerl C, Collado MC, Zuniga M, Blas E, and Perez Martinez G. 2014. Changes in cecal microbiota and mucosal gene expression revealed new aspects of epizootic rabbit enteropathy. PLoS One 9:e105707. 10.1371/journal.pone.0105707

Biddle A, Stewart L, Blanchard J, and Leschine S. 2013. Untangling the genetic basis of fibrolytic specialization by Lachnospiraceae and Ruminococcaceae in diverse gut communities. Diversity 5:627-640. 10.3390/d5030627

Borrel G, Brugere JF, Gribaldo S, Schmitz RA, and Moissl-Eichinger C. 2020. The hostassociated archaeome. Nature Reviews Microbiology 18:622-636. 10.1038/s41579-0200407-y

Buan NR, and Robinson NP. 2018. Methanogens: pushing the boundaries of biology. Emerging Topics in Life Sciences 2:629-646. 10.1042/etls20180031

Budd K, Gunn JC, Finch T, Klymus K, Sitati N, and Eggert LS. 2020. Effects of diet, habitat, and phylogeny on the fecal microbiome of wild African savanna (Loxodonta africana) and forest elephants (L. cyclotis). Ecology and Evolution 10:5637-5650. 10.1002/ece3.6305

Camacho C, Coulouris G, Avagyan V, Ma N, Papadopoulos J, Bealer K, and Madden TL. 2009. BLAST+: architecture and applications. BMC Bioinformatics 10:421. 10.1186/14712105-10-421

Capella-Gutierrez S, Silla-Martinez JM, and Gabaldon T. 2009. trimAl: a tool for automated alignment trimming in large-scale phylogenetic analyses. Bioinformatics 25:1972-1973. 10.1093/bioinformatics/btp348

Cervantes FA, and Martínez-Vázquez J. 1996. Historia Natural del conejo zacatuche o teporingo (Romerolagus diazi). Mexico

Chang A, Jeske L, Ulbrich S, Hofmann J, Koblitz J, Schomburg I, Neumann-Schaal M, Jahn D, and Schomburg D. 2021. BRENDA, the ELIXIR core data resource in 2021: new developments and updates. Nucleic Acids Research 49:D498-D508. 10.1093/nar/gkaa1025

Chao A, and Jost L. 2012. Coverage-based rarefaction and extrapolation: standardizing samples by completeness rather than size. Ecology 93:2533-2547. 10.1890/11-1952.1

Chen S, Zhou Y, Chen Y, and Gu J. 2018. fastp: an ultra-fast all-in-one FASTQ preprocessor. Bioinformatics 34:i884-i890. 10.1093/bioinformatics/bty560

Chiu CH, and Chao A. 2016. Estimating and comparing microbial diversity in the presence of sequencing errors. PeerJ 4:e1634. 10.7717/peerj.1634

Combes S, Michelland RJ, Monteils V, Cauquil L, Soulie V, Tran NU, Gidenne T, and FortunLamothe L. 2011. Postnatal development of the rabbit caecal microbiota composition and activity. FEMS Microbiology Ecology 77:680-689. 10.1111/j.1574-6941.2011.01148.x

Crowley EJ, King JM, Wilkinson T, Worgan HJ, Huson KM, Rose MT, and McEwan NR. 2017. Comparison of the microbial population in rabbits and guinea pigs by next generation sequencing. PLoS One 12:e0165779. 10.1371/journal.pone.0165779

Cumming G, Fidler F, and Vaux DL. 2007. Error bars in experimental biology. Journal of Cell Biology 177:7-11. 10.1083/jcb.200611141

de las Rivas B, Rodriguez H, Anguita J, and Munoz R. 2019. Bacterial tannases: classification and biochemical properties. Applied Microbiology and Biotechnology 103:603-623. 10.1007/s00253-018-9519-y

Peer] reviewing PDF | (2021:03:59685:1:1:NEW 9 Jul 2021) 
460

461

462

463

464

465

466

467

468

469

470

471

472

473

474

475

476

477

478

479

480

481

482

483

484

485

486

487

488

489

490

491

492

493

494

495

496

497

498

499

500

501

502

503

504

505

Ferrer Y, and Pérez H. 2010. Los microorganismos en la digestión anaerobia y la producción de biogás. Consideraciones en la elección del inóculo para el mejoramiento de la calidad y el rendimiento. ICIDCA Sobre los Derivados de la Caña de Azúcar 43:9-20

Ferry JG. 2020. Methanosarcina acetivorans: A model for mechanistic understanding of aceticlastic and reverse methanogenesis. Frontiers in Microbiology 11:1806. 10.3389/fmicb.2020.01806

Funosas G, Triado-Margarit X, Castro F, Villafuerte R, Delibes-Mateos M, Rouco C, and Casamayor EO. 2021. Individual fate and gut microbiome composition in the European wild rabbit (Oryctolagus cuniculus). Scientific Reports 11:766. 10.1038/s41598-02080782-4

Gaona O, Gomez-Acata ES, Cerqueda-Garcia D, Neri-Barrios CX, and Falcon LI. 2019. Fecal microbiota of different reproductive stages of the central population of the lesser-long nosed bat, Leptonycteris yerbabuenae. PLoS One 14:e0219982. 10.1371/journal.pone.0219982

Granados-Sánchez D, López-Ríos GF, Hernández-García MA, and Sánchez-González A. 2004. Ecología de la fauna silvestre de la Sierra Nevada y la Sierra del Ajusco Chapingo Serie Ciencias Forestales y del Ambiente 10:111-117

Granados-Sánchez D, Ruíz-Puga P, and Barrera-Escorcia H. 2008. Ecología de la herviboria. Revista Chapingo Serie Ciencias Forestales y del Ambiente 14:51-63

Hammer O, Harper DAT, and Ryan PD. 2001. PAST: Paleontological statistics software package for education and data analysis. Palaeontologia Electronica 4:9

Hsieh TC, Ma KH, Chao A, and McInerny G. 2016. iNEXT: an R package for rarefaction and extrapolation of species diversity (Hill numbers). Methods in Ecology and Evolution 7:1451-1456. 10.1111/2041-210x.12613

Human Microbiome Project C. 2012. Structure, function and diversity of the healthy human microbiome. Nature 486:207-214. 10.1038/nature11234

Ilmberger N, Gullert S, Dannenberg J, Rabausch U, Torres J, Wemheuer B, Alawi M, Poehlein A, Chow J, Turaev D, Rattei T, Schmeisser C, Salomon J, Olsen PB, Daniel R, Grundhoff A, Borchert MS, and Streit WR. 2014. A comparative metagenome survey of the fecal microbiota of a breast- and a plant-fed Asian elephant reveals an unexpectedly high diversity of glycoside hydrolase family enzymes. PLoS One 9:e106707. 10.1371/journal.pone.0106707

Ingala MR, Simmons NB, Wultsch C, Krampis K, Speer KA, and Perkins SL. 2018. Comparing microbiome sampling methods in a wild mammal: fecal and intestinal samples record different signals of host ecology, evolution. Frontiers in Microbiology 9:803. $10.3389 /$ fmicb.2018.00803

Jasso-Chavez R, Santiago-Martinez MG, Lira-Silva E, Pineda E, Zepeda-Rodriguez A, BelmontDiaz J, Encalada R, Saavedra E, and Moreno-Sanchez R. 2015. Air-adapted Methanosarcina acetivorans shows high methane production and develops resistance against oxygen stress. PLoS One 10:e0117331 10.1371/journal.pone.0117331

Kanehisa M, Sato Y, and Morishima K. 2016. BlastKOALA and GhostKOALA: KEGG Tools for functional characterization of genome and metagenome sequences. Journal of Molecular Biology 428:726-731. 10.1016/j.jmb.2015.11.006

Katoh K, and Standley DM. 2013. MAFFT multiple sequence alignment software version 7: improvements in performance and usability. Molecular Biology and Evolution 30:772780. $10.1093 / \mathrm{molbev} / \mathrm{mst} 010$ 
506

507

508

509

510

511

512

513

514

515

516

517

518

519

520

521

522

523

524

525

526

527

528

529

530

531

532

533

534

535

536

537

538

539

540

541

542

543

544

545

546

547

548

549

550

551

Kusar D, and Avgustin G. 2010. Molecular profiling and identification of methanogenic archaeal species from rabbit caecum. FEMS Microbiology Ecology 74:623-630. 10.1111/j.15746941.2010.00980.x

Langmead B, and Salzberg SL. 2012. Fast gapped-read alignment with Bowtie 2. Nature Methods 9:357-359. 10.1038/nmeth.1923

Ley RE, Hamady M, Lozupone C, Turnbaugh PJ, Ramey RR, Bircher JS, Schlegel ML, Tucker TA, Schrenzel MD, Knight R, and Gordon JI. 2008. Evolution of mammals and their gut microbes. Science 320:1647-1651. 10.1126/science. 1155725

Li D, Liu CM, Luo R, Sadakane K, and Lam TW. 2015. MEGAHIT: an ultra-fast single-node solution for large and complex metagenomics assembly via succinct de Bruijn graph. Bioinformatics 31:1674-1676. 10.1093/bioinformatics/btv033

Li H, Qu J, Li T, Yao M, Li J, and Li X. 2017. Gut microbiota may predict host divergence time during Glires evolution. FEMS Microbiology Ecology 93. 10.1093/femsec/fix009

Li W, and Godzik A. 2006. Cd-hit: a fast program for clustering and comparing large sets of protein or nucleotide sequences. Bioinformatics 22:1658-1659 10.1093/bioinformatics/btl158

Lu J, Breitwieser FP, Thielen P, and Salzberg SL. 2017. Bracken: estimating species abundance in metagenomics data. PeerJ Computer Science 3. 10.7717/peerj-cs.104Ma ZS, and Li L. 2018.

Ma ZS, and Li L. 2018. Measuring metagenome diversity and similarity with Hill numbers. Molecular Ecology Resources 18:1339-1355. 10.1111/1755-0998.12923

Ma ZS, Li L, and Gotelli NJ. 2019. Diversity-disease relationships and shared species analyses for human microbiome-associated diseases. The ISME Journal 13:1911-1919. 10.1038/s41396-019-0395-y

Magne F, Gotteland M, Gauthier L, Zazueta A, Pesoa S, Navarrete P, and Balamurugan R. 2020. The Firmicutes/Bacteroidetes Ratio: A Relevant Marker of Gut Dysbiosis in Obese Patients? Nutrients 12. 10.3390/nu12051474

Mancinez Arellano A. 2017. Dieta del conejo zacatuche (Romerolagus diazi) en hábitats contrastantes del corredor biológico Chichinautzin. Licenciatura. Universidad Autónoma del Estado de Morelos.

Mariat D, Firmesse O, Levenez F, Guimaraes V, Sokol H, Dore J, Corthier G, and Furet JP. 2009. The Firmicutes/Bacteroidetes ratio of the human microbiota changes with age. BMC Microbiology 9:123. 10.1186/1471-2180-9-123

Martinez-Romero E, Aguirre-Noyola JL, Bustamante-Brito R, Gonzalez-Roman P, HernandezOaxaca D, Higareda-Alvear V, Montes-Carreto LM, Martinez-Romero JC, Rosenblueth M, and Servin-Garciduenas LE. 2020. We and herbivores eat endophytes. Microbial Biotechnology 10.1111/1751-7915.13688

Mikheenko A, Saveliev V, and Gurevich A. 2016. MetaQUAST: evaluation of metagenome assemblies. Bioinformatics 32:1088-1090. 10.1093/bioinformatics/btv697

Moon CD, Young W, Maclean PH, Cookson AL, and Bermingham EN. 2018. Metagenomic insights into the roles of Proteobacteria in the gastrointestinal microbiomes of healthy dogs and cats. Microbiologyopen 7:e00677. 10.1002/mbo3.677

Muegge BD, Kuczynski J, Knights D, Clemente JC, Gonzalez A, Fontana L, Henrissat B, Knight $\mathrm{R}$, and Gordon JI. 2011. Diet drives convergence in gut microbiome functions across mammalian phylogeny and within humans. Science 332:970-974. 10.1126/science. 1198719 
552

553

554

555

556

557

558

559

560

561

562

563

564

565

566

567

568

569

570

571

572

573

574

575

576

577

578

579

580

581

582

583

584

585

586

587

588

589

590

591

592

593

594

595

North MK, Dalle Zotte A, and Hoffman LC. 2019. Composition of rabbit caecal microbiota and the effects of dietary quercetin supplementation and sex thereupon. World Rabbit Science 27. 10.4995/wrs.2019.11905

Nurk S, Bankevich A, Antipov D, Gurevich AA, Korobeynikov A, Lapidus A, Prjibelski AD, Pyshkin A, Sirotkin A, Sirotkin Y, Stepanauskas R, Clingenpeel SR, Woyke T, McLean JS, Lasken R, Tesler G, Alekseyev MA, and Pevzner PA. 2013. Assembling single-cell genomes and mini-metagenomes from chimeric MDA products. Journal of Computational Biology 20:714-737. 10.1089/cmb.2013.0084

Nurk S, Meleshko D, Korobeynikov A, and Pevzner PA. 2017. metaSPAdes: a new versatile metagenomic assembler. Genome Research 27:824-834. 10.1101/gr.213959.116

Osawa R, Rainey F, Fujisawa T, Lang E, Busse HJ, Walsh TP, and Stackebrandt E. 1995. Lonepinella koalarum gen. nov., sp. nov., a New Tannin-Protein Complex Degrading Bacterium. Systematic and Applied Microbiology 18:368-373. 10.1016/s07232020(11)80430-3

Osuna F, González D, de los Monteros AE, and Guerrero JA. 2020. Phylogeography of the Volcano Rabbit (Romerolagus diazi): the Evolutionary History of a Mountain Specialist Molded by the Climatic-Volcanism Interaction in the Central Mexican Highlands. Journal of Mammalian Evolution 27:745-757. 10.1007/s10914-019-09493-6

Palacio-Arango MA, Cano-Vanegas IC, Múnera-Porras LM, Pino-Rodriguez NJ, and PeñuelaMesa GA. 2018. Evaluación de la capacidad degradadora de taninos por microorganismos aislados a partir de un efluente de curtiembre del municipio de Copacabana, Antioquia. Actualidades Biológicas 40. 10.17533/udea.acbi.v40n108a02

Redinbo MR. 2014. The microbiota, chemical symbiosis, and human disease. Journal of Molecular Biology 426:3877-3891. 10.1016/j.jmb.2014.09.011

Rey FE, Faith JJ, Bain J, Muehlbauer MJ, Stevens RD, Newgard CB, and Gordon JI. 2010. Dissecting the in vivo metabolic potential of two human gut acetogens. Journal of Biological Chemistry 285:22082-22090. 10.1074/jbc.M110.117713

Rodríguez-Durán LV, Valdivia-Urdiales B, Contreras-Esquivel JC, Rodríguez-Herrera R, and Aguilar CN. 2010. Química y biotecnología de la tanasa. Revista Científica de la Universidad Autónoma de Coahuila 2:10

Santiago-Martinez MG, Encalada R, Lira-Silva E, Pineda E, Gallardo-Perez JC, Reyes-Garcia MA, Saavedra E, Moreno-Sanchez R, Marin-Hernandez A, and Jasso-Chavez R. 2016. The nutritional status of Methanosarcina acetivorans regulates glycogen metabolism and gluconeogenesis and glycolysis fluxes. The FEBS Journal 283:1979-1999. $10.1111 /$ febs. 13717

Saratale GD, Saratale RG, and Oh SE. 2012. Production and characterization of multiple cellulolytic enzymes by isolated Streptomyces sp. MDS. Biomass and Bioenergy 47:302315. 10.1016/j.biombioe.2012.09.030

Seemann T. 2014. Prokka: rapid prokaryotic genome annotation. Bioinformatics 30:2068-2069. 10.1093/bioinformatics/btu153

SEMARNAT. 2010. Norma Oficial Mexicana NOM-059-SEMARNAT-2010, Protección ambiental-especies nativas de México de flora y fauna silvestres-categorías de riesgo y especificaciones para su inclusión, exclusión o cambio-lista de especies en riesgo. México: Diario Oficial de la Federación 
596

597

598

599

600

601

602

603

604

605

606

607

608

609

610

611

612

613

614

615

616

617

618

619

620

621

622

623

624

625

626

627

628

629

630

631

632

633

634

635

636

637

638

639

Shanmuganandam S, Hu Y, Strive T, Schwessinger B, and Hall RN. 2020. Uncovering the microbiome of invasive sympatric European brown hares and European rabbits in Australia. PeerJ 8:e9564. 10.7717/peerj.9564

Shin NR, Whon TW, and Bae JW. 2015. Proteobacteria: microbial signature of dysbiosis in gut microbiota. Trends in Biotechnology 33:496-503. 10.1016/j.tibtech.2015.06.011

Stalder GL, Pinior B, Zwirzitz B, Loncaric I, Jakupovic D, Vetter SG, Smith S, Posautz A, Hoelzl F, Wagner M, Hoffmann D, Kubber-Heiss A, and Mann E. 2019. Gut microbiota of the European Brown Hare (Lepus europaeus). Scientific Reports 9:2738. 10.1038/s41598-019-39638-9

Tamames J, Cobo-Simon M, and Puente-Sanchez F. 2019. Assessing the performance of different approaches for functional and taxonomic annotation of metagenomes. BMC Genomics 20:960. 10.1186/s12864-019-6289-6

Tilg H. 2010. Obesity, metabolic syndrome, and microbiota: multiple interactions. Journal of Clinical Gastroenterology 44 Suppl 1:S16-18. 10.1097/MCG.0b013e3181dd8b64

Trifinopoulos J, Nguyen LT, von Haeseler A, and Minh BQ. 2016. W-IQ-TREE: a fast online phylogenetic tool for maximum likelihood analysis. Nucleic Acids Research 44:W232235. 10.1093/nar/gkw256

Uriostegui Velarde JM, Vera García ZS, Ávila Torresagatón LG, Rizo Aguilar A, Hidalgo Mihart MG, and Guerrero JA. 2015. Importancia del conejo zacatuche (Romerolagus diazi) en la dieta del coyote (Canis lastrans) y del lince (Lynx rufus). Therya 6:609-624. 10.12933/therya-15-306

Velasco-Galilea M, Piles M, Vinas M, Rafel O, Gonzalez-Rodriguez O, Guivernau M, and Sanchez JP. 2018. Rabbit microbiota changes throughout the intestinal tract. Frontiers in Microbiology 9:2144. 10.3389/fmicb.2018.02144

Velázquez A, and Guerrero JA. 2019. Romerolagus diazi. The IUCN Red List of Threatened Species 2019. https://dx.doi.org/10.2305/IUCN.UK.2019-2.RLTS.T19742A45180356.en.

Velázquez AF, Romero J, and López-Paniagua J. 1996. Ecología y conservación del conejo zacatuche Romerolagus diazi y su hábitat. México

Ventura M, O'Flaherty S, Claesson MJ, Turroni F, Klaenhammer TR, van Sinderen D, and O'Toole PW. 2009. Genome-scale analyses of health-promoting bacteria: probiogenomics. Nature Reviews Microbiology 7:61-71. 10.1038/nrmicro2047

Waino M, Tindall BJ, and Ingvorsen K. 2000. Halorhabdus utahensis gen. nov., sp. nov., an aerobic, extremely halophilic member of the Archaea from Great Salt Lake, Utah. International Journal of Systematic and Evolutionary Microbiology 50 Pt 1:183-190. 10.1099/00207713-50-1-183

Wingett SW, and Andrews S. 2018. FastQ Screen: A tool for multi-genome mapping and quality control. F1000Research 7:1338. 10.12688/f1000research.15931.2

Wood DE, Lu J, and Langmead B. 2019. Improved metagenomic analysis with Kraken 2. Genome Biology 20:257. 10.1186/s13059-019-1891-0

Yuan C, Lei J, Cole J, and Sun Y. 2015. Reconstructing 16S rRNA genes in metagenomic data. Bioinformatics 31:i35-43. 10.1093/bioinformatics/btv23

Zeng B, Han S, Wang P, Wen B, Jian W, Guo W, Yu Z, Du D, Fu X, Kong F, Yang M, Si X, Zhao J, and Li Y. 2015. The bacterial communities associated with fecal types and body weight of rex rabbits. Scientific Reports 5:9342. 10.1038/srep09342

PeerJ reviewing PDF | (2021:03:59685:1:1:NEW 9 Jul 2021) 


\section{Figure 1}

Phyla of the bacteria and archaea domain found in the fecal microbiome of the volcano rabbit

Relative abundance was obtained by dividing the number of contigs assigned per phylum by the total number of contigs for the Bacteria and Archaea domains, respectively. The figures were constructed considering only phyla with a relative abundance equal to or greater than $0.5 \%$, which means that rare bacteria and archaea were not considered. A) Percentage of abundance of the main phyla from the Bacteria domain found in feces of the volcano rabbit. B) Percentage of abundance of the main phyla from the Archaea domain found in feces of the volcano rabbit 

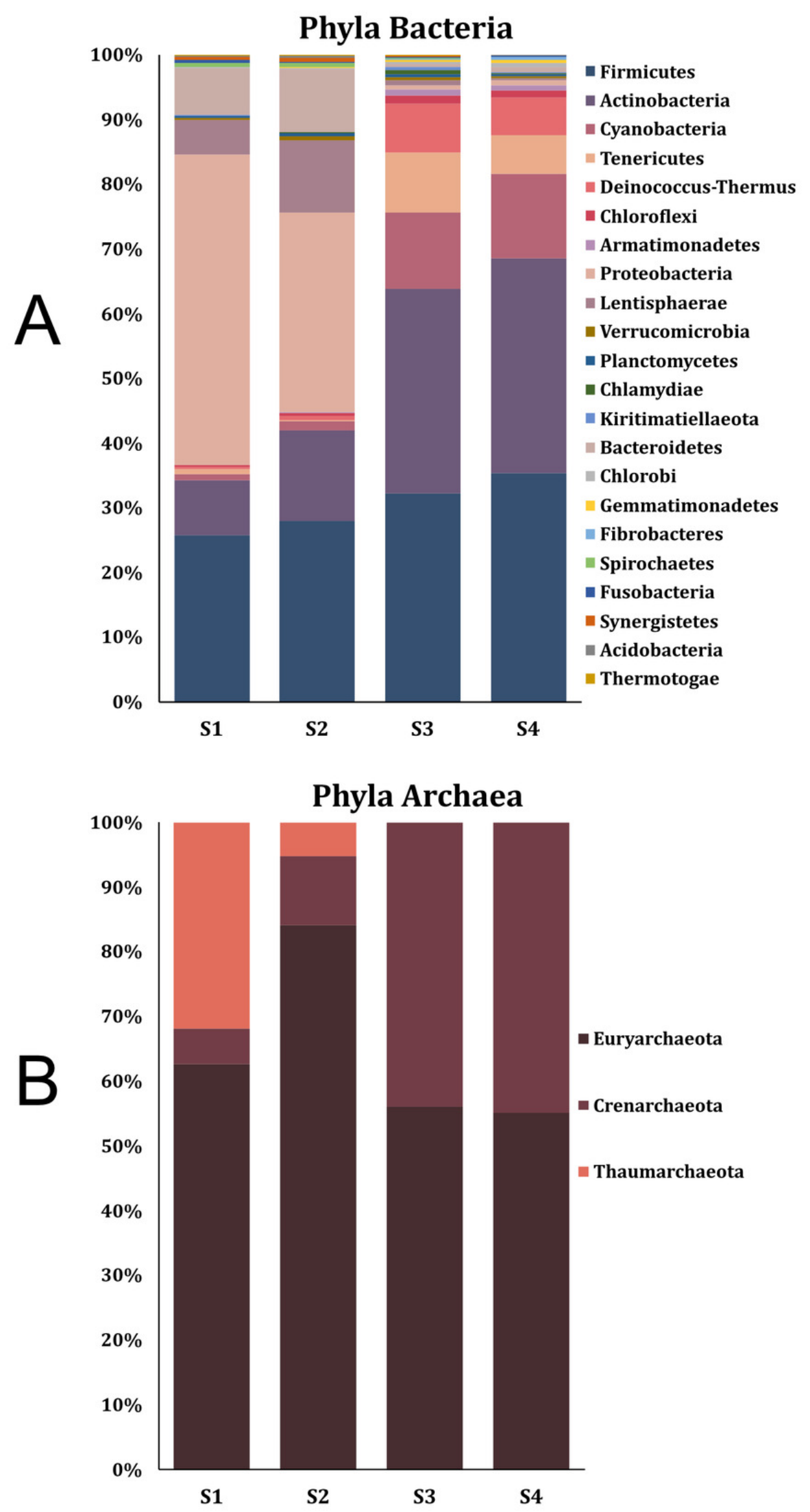


\section{Figure 2}

Genera of the bacteria and archaea domain found in the fecal microbiome of the volcano rabbit

Relative abundance was obtained by dividing the number of contigs assigned per genus by the total number of contigs for the Bacteria and Archaea domains, respectively. The figures were constructed considering only genera with a relative abundance equal to or greater than $0.5 \%$, which means that rare bacteria and archaea were not considered. A) Percentage of abundance of the most representative genera per sample within Bacteria domain. B) Percentage of abundance of the most representative genera per sample within Archaea domain 


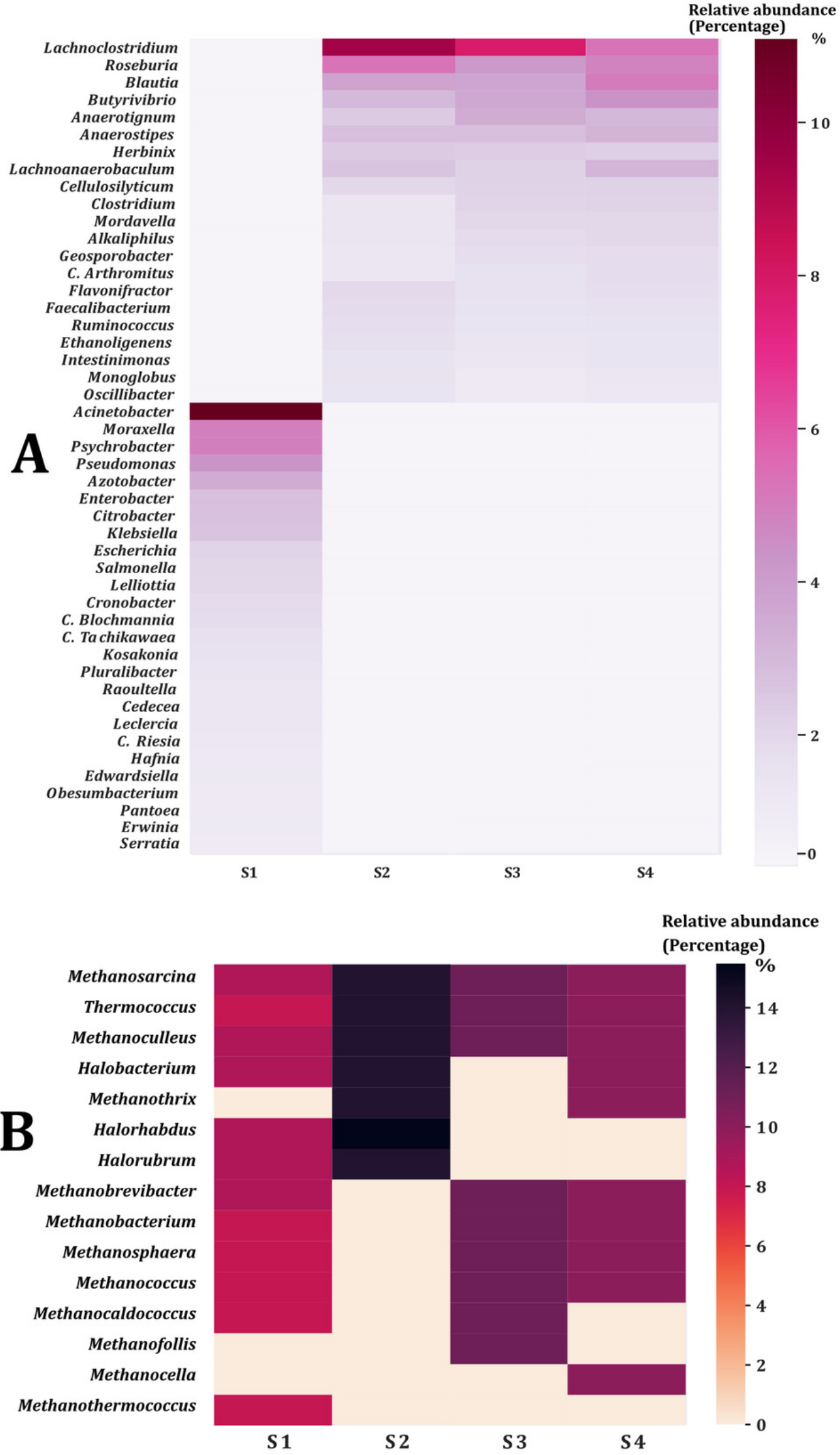


Figure 3

Sample coverage (SC) per sample, taxonomic level, and diversity (q0)

SC ranged from 0.0 to 1.0. A) Sample coverage for the phyla of the Bacteria domain. B)

Sample coverage for the phyla of Archaea domain. C) Sample coverage for the genera of the Bacteria domain. D) Sample coverage for the genera of the Archaea domain

A

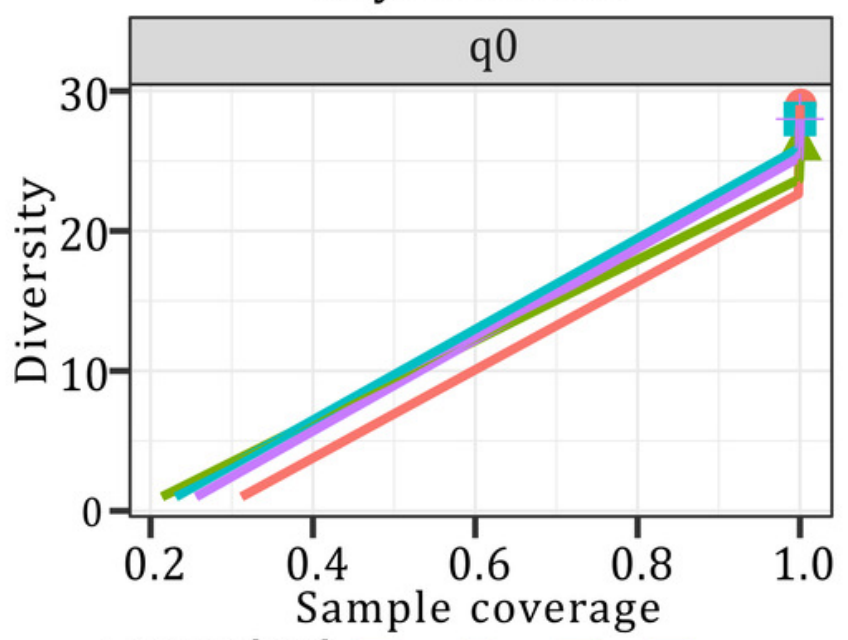

-interpolated $\square \mathrm{S} 1 \square \mathrm{S} 2 \square \mathrm{S} 3 \boxplus \mathrm{S} 4$

C

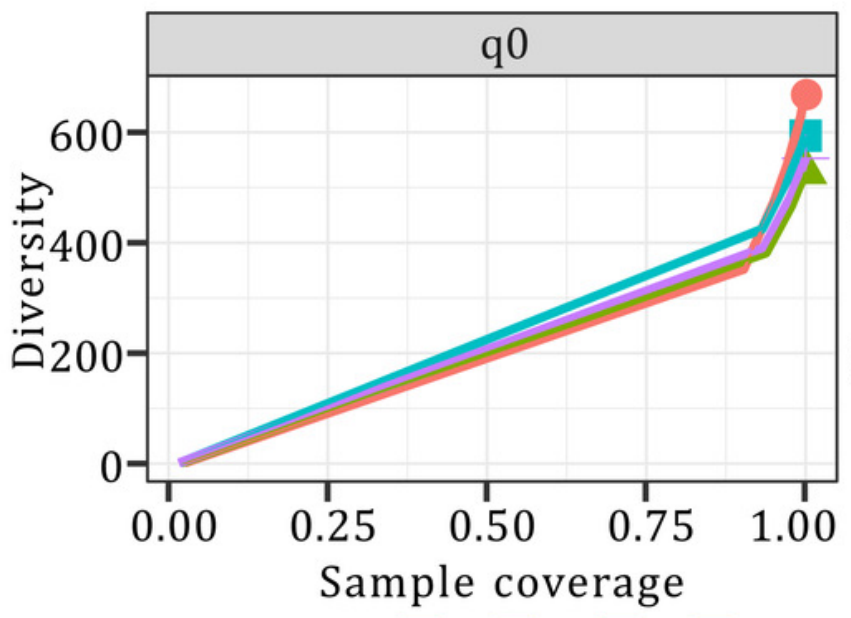

-interpolated $\square \mathrm{S} 1 \mathrm{R}$ S2 $\square \mathrm{S} 3 \boxplus \mathrm{S} 4$
B Phyla Archaea

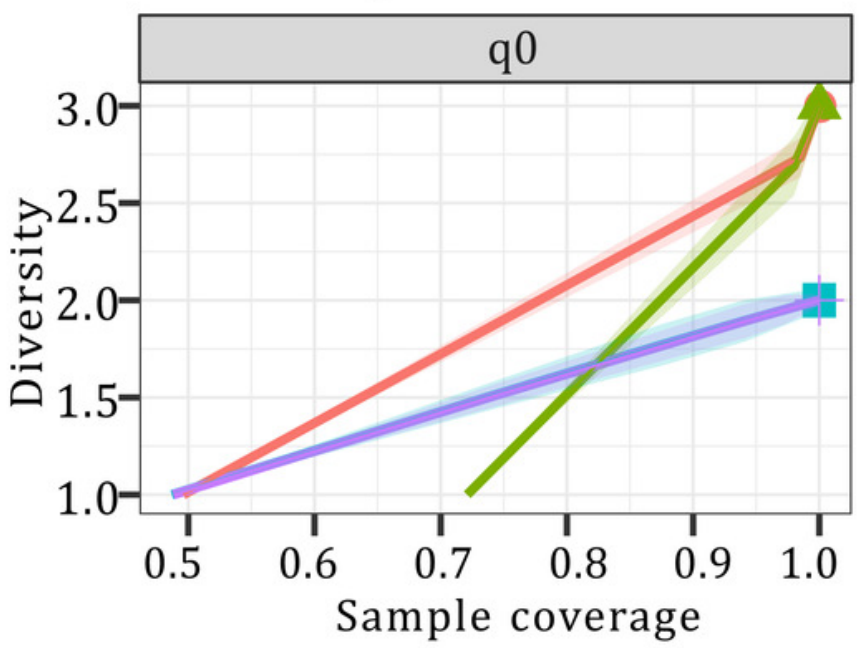

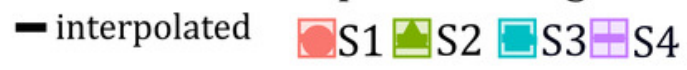

D Genera Archaea

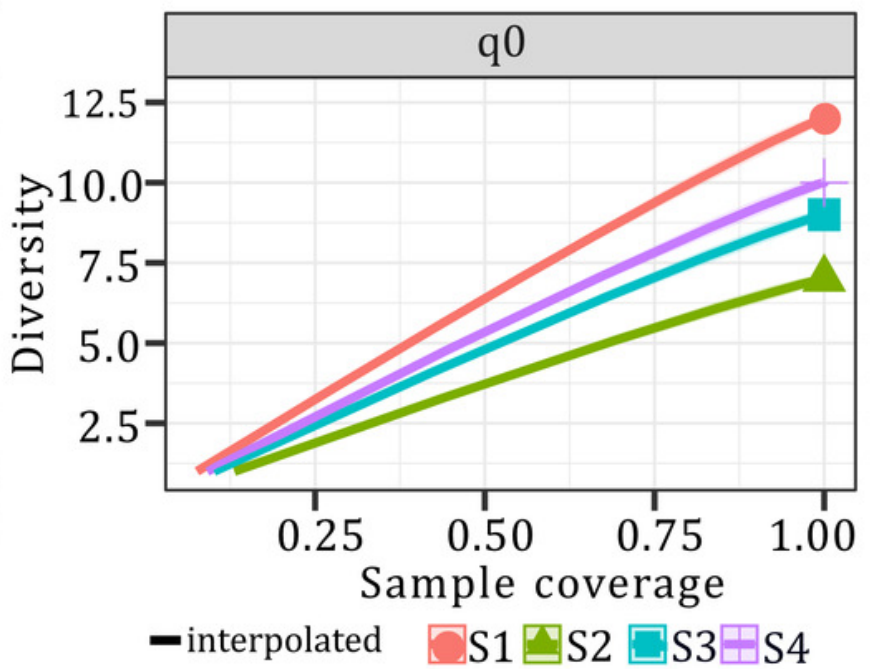


Figure 4

Species Richness (q0) per sample and taxonomic level

A) Species richness for the phyla of the Bacteria domain. B) Species richness for the phyla of Archaea domain. C) Species richness for the genera of the Bacteria domain. D) Species richness for the genera of the Archaea domain 

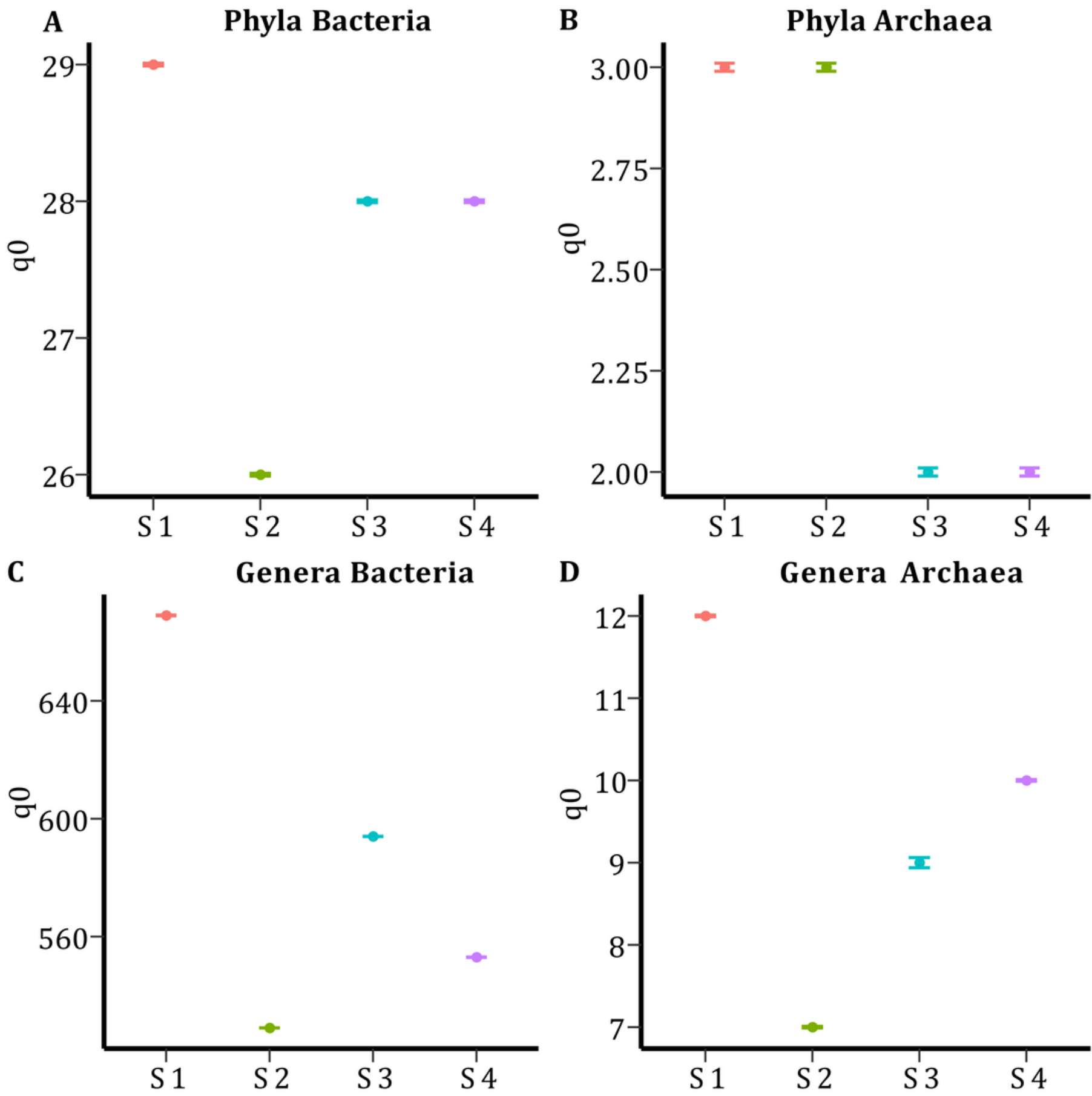

D

Genera Archaea

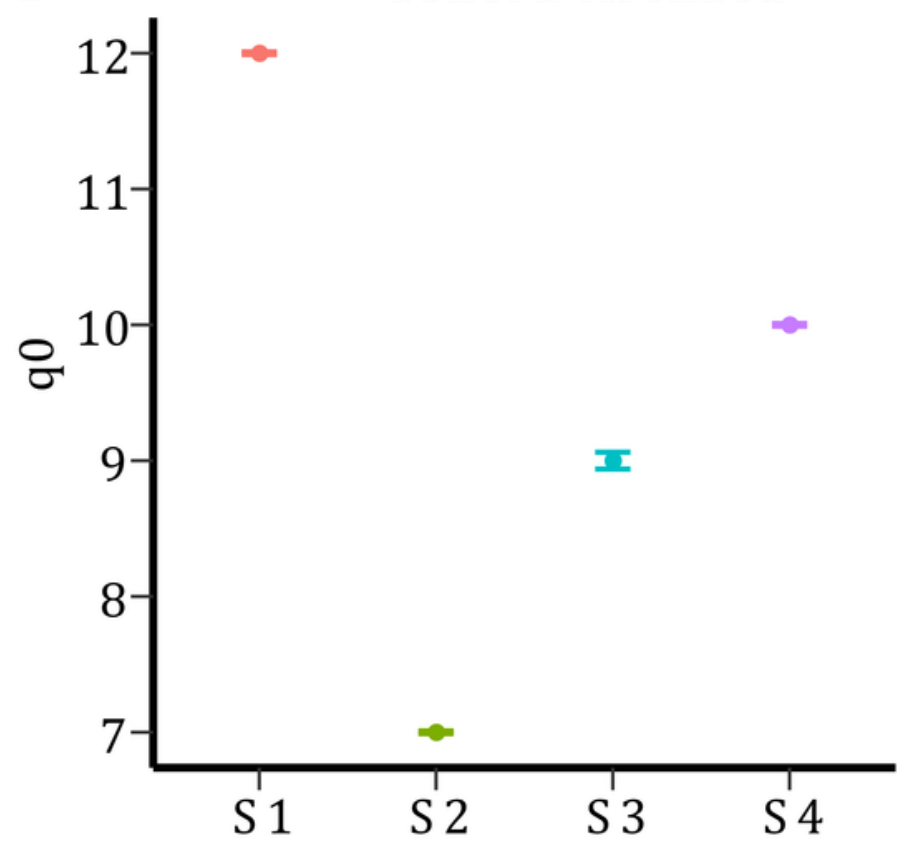




\section{Figure 5}

Enzymes annotated in the fecal metagenome of the volcano rabbit

Comparison of enzymes according to their catalytic action: Transferases, Hydrolases,

Oxidoreductases, Ligases, Lyases and Isomerases per sample and by number of contigs (COUNTS) using PROKKA

COUNTS

Transferases

Hydrolases

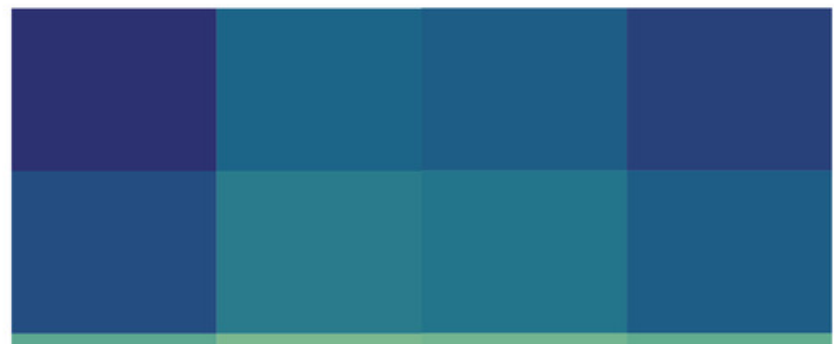

\section{Oxidoreductases}

Ligases

Lyases

Isomerases

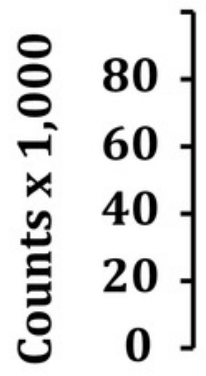

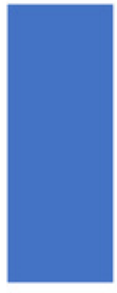

S1

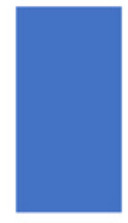

S2

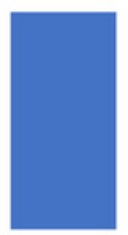

S3
$-25,000$

$-20,000$

$-15,000$

$-10,000$

$-5,000$ 


\section{Figure 6}

Functional annotation categories in the fecal metagenome of the volcano rabbit

Comparison of categories of functional annotation by sample and by number of contigs (COUNTS) using GhostKOALA

Genetic Information processing Prot. fam: genetic inf. processes Carbohydrate Metabolism Prot. fam: sig. and cellular processes Amino acid Metabolism Environmental Inf. Processing Nucleotide metabolism Metabolism of cofactors and vitamins Protein families: metabolism Energy metabolism Lipid metabolism Cellular processes Xeno.biodeg and metabolism Glycan biosynthesis and metabolism Biosynthesis of other sec metabolites Metabolism of terpe. and polyketides Organismal systems

Metabolism of other amino acids Unclassified: sig. and cellular processes Unclassified: metabolism Unclassified

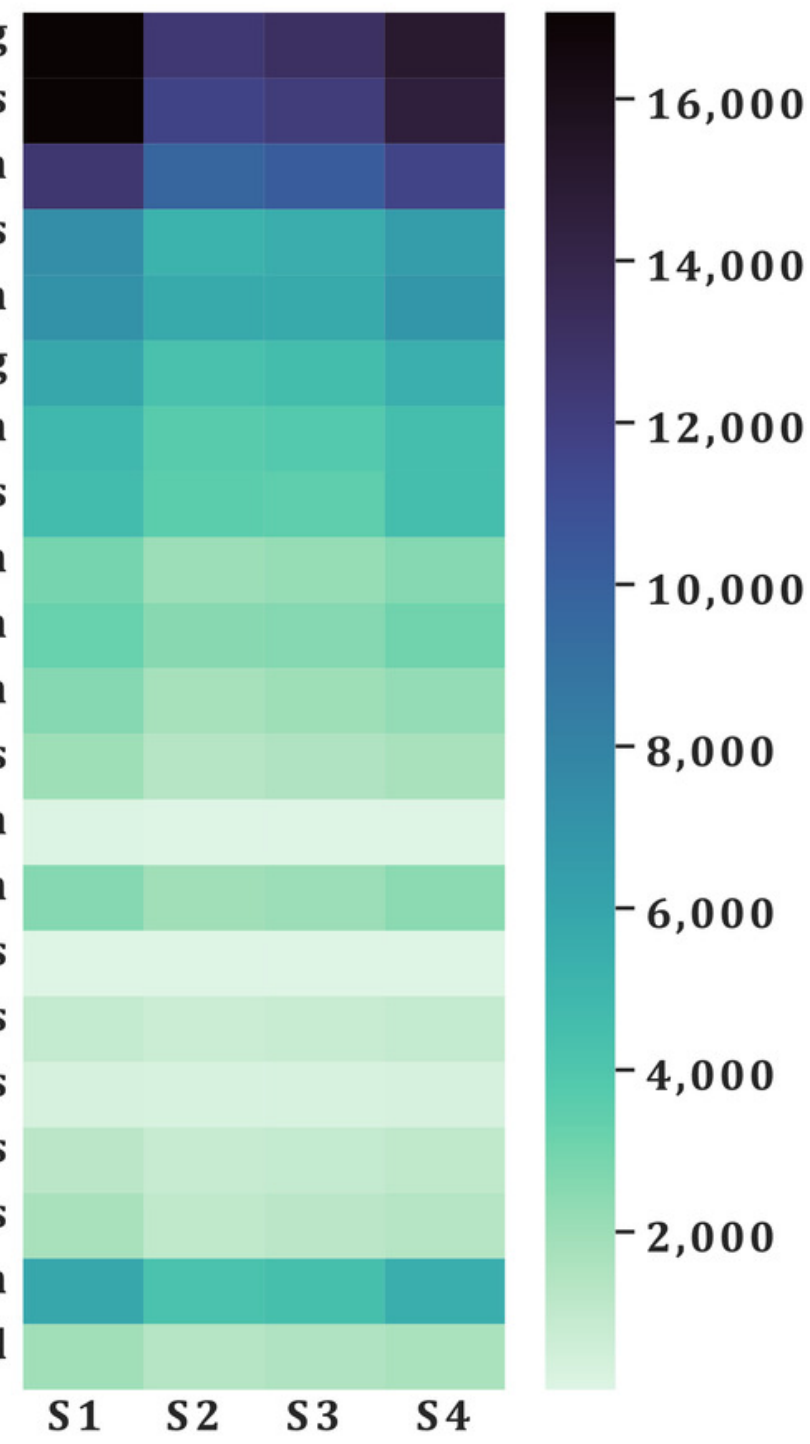

COUNTS 


\section{Figure 7}

Enzymes (class 3) associated in the degradation of cellulose and hemicellulose of plants

Comparison of the enzymes associated with plant fiber degradation by sample and by number of contigs (COUNTS)

Endo-1,4- $\beta$ xylanase

Arabinofuranosidase

Endoglucanase

$\beta$-glucosidase

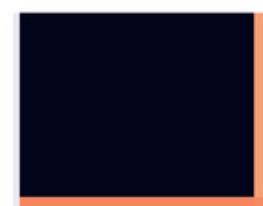

COUNTS

$$
\left.\begin{array}{c}
800 \\
600 \\
3 \\
300 \\
200 \\
0
\end{array}\right]
$$

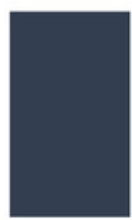

S1

S2

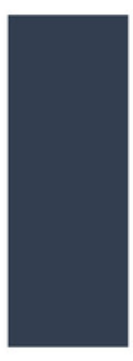

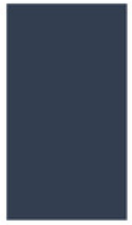

S3

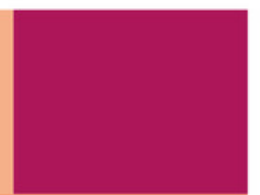

$-350$

$-300$

$-250$

$-200$

- 150

$-100$

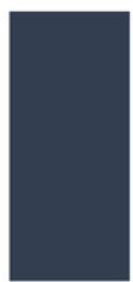

S4 


\section{Table $\mathbf{1}$ (on next page)}

Most abundant phyla, families, and genera in the fecal microbiomes of the volcano rabbit. 


\begin{tabular}{|c|c|c|c|}
\hline Phylum & Family & Genus & $\begin{array}{l}\text { Global relative } \\
\text { abundance of the genus } \\
\text { (\%) }\end{array}$ \\
\hline \multirow{24}{*}{ Proteobacteria } & \multirow{3}{*}{ Moraxellaceae } & Acinetobacter & 2.82 \\
\hline & & Moraxella & 1.25 \\
\hline & & Psychrobacter & 1.23 \\
\hline & \multirow[t]{2}{*}{ Pseudomonadaceae } & Azotobacter & 0.87 \\
\hline & & Pseudomonas & 1.09 \\
\hline & \multirow{3}{*}{ Hafniaceae } & Hafnia & 0.24 \\
\hline & & Obesumbacterium & 0.20 \\
\hline & & Edwardsiella & 0.26 \\
\hline & \multirow[t]{2}{*}{ Erwiniaceae } & Erwinia & 0.23 \\
\hline & & Pantoea & 0.24 \\
\hline & Yersiniaceae & Serratia & 0.22 \\
\hline & \multirow[t]{13}{*}{ Enterobacteriaceae } & Enterobacter & 0.70 \\
\hline & & Citrobacter & 0.67 \\
\hline & & Klebsiella & 0.65 \\
\hline & & Escherichia & 0.51 \\
\hline & & Lelliottia & 0.48 \\
\hline & & Salmonella & 0.50 \\
\hline & & Cronobacter & 0.46 \\
\hline & & Kosakonia & 0.38 \\
\hline & & Raoultella & 0.31 \\
\hline & & Pluralibacter & 0.35 \\
\hline & & Cedecea & 0.29 \\
\hline & & Leclercia & 0.25 \\
\hline & & Candidatus Riesia & 0.25 \\
\hline \multirow[t]{19}{*}{ Firmicutes } & \multirow[t]{8}{*}{ Lachnospiraceae } & Lachnoclostridium & 5.59 \\
\hline & & Blautia & 3.02 \\
\hline & & Roseburia & 3.45 \\
\hline & & Butyrivibrio & 2.61 \\
\hline & & Herbinix & 1.60 \\
\hline & & Cellulosilyticum & 1.39 \\
\hline & & Anaerostipes & 2.04 \\
\hline & & Lachnoanaerobaculum & 1.83 \\
\hline & \multirow[t]{5}{*}{ Clostridiaceae } & Clostridium & 1.23 \\
\hline & & Mordavella & 1.16 \\
\hline & & Geosporobacter & 1.02 \\
\hline & & Alkaliphilus & 1.12 \\
\hline & & C. Arthromitus & 1.00 \\
\hline & \multirow[t]{6}{*}{ Oscillospiraceae } & Ruminococcus & 1.00 \\
\hline & & Faecalibacterium & 1.08 \\
\hline & & Oscillibacter & 0.74 \\
\hline & & Flavonifractor & 1.13 \\
\hline & & Ethanoligenens & 0.96 \\
\hline & & Monoglobus & 0.79 \\
\hline
\end{tabular}

1 


\section{Table 2 (on next page)}

Functional annotation comparison between all samples

The numbers indicate the total of annotated contigs in each category per sample. 


\begin{tabular}{lcccc}
\hline Categories & S1 & S2 & S3 & S4 \\
\hline CDS & 131028 & 96532 & 101789 & 119898 \\
tmRNA & 90 & 63 & 69 & 87 \\
rRNA & 511 & 387 & 387 & 422 \\
tRNA & 6389 & 4850 & 5098 & 5430 \\
\hline
\end{tabular}

